\title{
PROMOVENDO A ARGUMENTAÇÃO NO ENSINO SUPERIOR DE QUÍMICA
}

\author{
Luciana Passos Sá \\ Departamento de Química, Universidade Federal de São Carlos, CP 676, 13565-905 São Carlos - SP, Brasil \\ Salete Linhares Queiroz* \\ Instituto de Química de São Carlos, Universidade de São Paulo, CP 780, 13560-970 São Carlos - SP, Brasil
}

Recebido em 9/8/06; aceito em 10/4/07; publicado na web em 9/11/07

\begin{abstract}
PROMOTING ARGUMENTATION IN UNDERGRADUATE CHEMISTRY TEACHING. Studies have demonstrated the importance of argumentation in science education. Based on this assertion, we have tried to develop argumentative abilities in chemistry undergraduate students through a teaching methodology based on case studies. The process culminated with class presentations by student groups about possible solutions for the cases. To assess the quality of students' argumentation, videotapes of group presentations were collected and analyzed using Toulmin's Argument Pattern (TAP). TAP illustrates the nature of an argument in terms of claims, data, warrants, backings, and rebuttals. The findings of this work support the idea that the case study approach is an effective strategy for enhancing students' ability to argument.
\end{abstract}

Keywords: higher education; argumentation; chemistry.

\section{INTRODUÇÃO}

As novas orientações das pesquisas em educação têm mostrado a importante contribuição das investigações que privilegiam a análise da dimensão discursiva dos processos de ensino-aprendizagem de ciências em situações reais de sala de aula. Tais estudos destacam o papel da linguagem como elemento fundamental para a aquisição do conhecimento científico escolar ${ }^{1,2}$.

Segundo Jorge e Puig ${ }^{3}$, para aprender ciência é necessário aprender a falar, escrever e ler ciência de maneira significativa. Isto implica também em aprender a reconhecer as diversas maneiras de expressar um mesmo significado, as diferenças entre a linguagem cotidiana e a linguagem científica e as principais características de cada tipo de discurso. Sendo a argumentação uma característica marcante do discurso científico, pesquisadores da área de educação em ciências apontam para a necessidade da organização de aulas em que os estudantes tenham a oportunidade de praticá-la $\mathrm{a}^{4-7}$.

Neste trabalho temos como objetivo discutir em que medida uma proposta de ensino pautada na resolução de casos investigativos (método de Estudo de Caso $)^{8}$ foi capaz de estimular a elaboração de argumentos por parte de graduandos em química e avaliar a qualidade dos argumentos por eles apresentados na resolução dos casos. Para tanto, tomamos como referenciais teóricos o modelo de Toulmin, apresentado no livro "The Uses of Argument" e o trabalho de Jiménez Aleixandre et al. ${ }^{10}$, que apresenta um maior detalhamento dos componentes do argumento propostos por Toulmin.

As etapas de aplicação da proposta de ensino, assim como a metodologia empregada na elaboração dos casos, encontram-se descritas no artigo Estudos de Caso em Química, de nossa autoria, e publicado nesta revista ${ }^{11}$. Desta forma, serão sucintamente relatadas aqui.

Tendo em vista a natureza do presente artigo, discutimos no tópico seguinte o papel que tem sido creditado à argumentação no ensino de ciências, de acordo com publicações recentes, e apresentamos os referenciais teóricos adotados para a análise dos dados coletados durante a realização do trabalho.

*e-mail: salete@iqsc.usp.br

\section{ARGUMENTAÇÃO E ENSINO DE CIÊNCIAS}

A argumentação é uma atividade social, intelectual e verbal, utilizada para justificar ou refutar uma opinião e que consiste em fazer declarações, levando em consideração o receptor e a finalidade com a qual se emitem. Para argumentar é necessário escolher entre diferentes opções ou explicações e raciocinar sobre os critérios que permitam avaliar como mais adequada a opção escolhida ${ }^{5}$.

Driver et $a l .{ }^{6}$ estão entre os pesquisadores que destacam a importância do estabelecimento, em ambientes de ensino, de situações que desenvolvam habilidades argumentativas dos alunos. Acreditam que a prática da argumentação pode fazer com que os estudantes entendam melhor a própria racionalidade da ciência e compreendam conceitos científicos mais adequadamente. Nesta perspectiva, a importância da implementação de propostas de ensino capazes de favorecer o aprimoramento da capacidade argumentativa dos alunos tem sido discutida nos últimos anos, tanto nos níveis fundamental e médio ${ }^{7,12}$, quanto no nível superior ${ }^{13}$.

São dignos de nota os estudos desenvolvidos com o intuito de identificar estratégias pedagógicas capazes de promover a habilidade de argumentação nos alunos dos cursos de ciências ${ }^{6,10}$ e, também, com o objetivo de avaliar a qualidade de argumentação em discussões de aspectos científicos ${ }^{6,14}$ e sócio-científicos ${ }^{7,13}$. A título de exemplo, citamos o artigo de Capecchi e Carvalho ${ }^{12}$, intitulado Argumentação em uma Sala de Aula de Conhecimento Físico com Crianças na Faixa de Oito a Dez. Anos, que analisa a qualidade das argumentações produzidas por alunos em discussões de aspectos científicos. Com relação à análise da qualidade das argumentações em discussões de aspectos sócio-científicos, o artigo de Santos et al. ${ }^{7}$, intitulado A Argumentação em Discussões Sócio-Científicas: Reflexões a Partir de um Estudo de Caso, apresenta um estudo que procura compreender como os professores introduzem aspectos sócio-científicos em sala de aula e como as estratégias por eles utilizadas melhoram a argumentação dos alunos.

A análise da argumentação dos estudantes é realizada sob diferentes enfoques por pesquisadores da área de educação em ciências. São encontrados estudos em que ela é feita do ponto de vista estrutural, via de regra, usando do modelo de Toulmin ${ }^{9}$. Outros a 
realizam tanto do ponto de vista estrutural quanto do ponto de vista das interações estabelecidas na discussão geral ${ }^{12,15}$, existindo ainda formas distintas para a sua realização ${ }^{16}$. Neste trabalho, conforme mencionamos anteriormente, os argumentos apresentados pelos estudantes foram analisados considerando o padrão de argumento racional desenvolvido por Toulmin ${ }^{9}$ e o trabalho de JiménezAleixandre et al. ${ }^{10}$. Ambos os referenciais encontram-se descritos, de forma resumida, a seguir.

\section{O modelo de Toulmin 9}

Um instrumento de análise muito utilizado para investigar a argumentação científica produzida por alunos no ensino de ciências é o modelo de Toulmin . Este modelo, ilustrado no Quadro 1, identifica os elementos fundamentais de um argumento, assim como as relações existentes entre eles.

Quadro 1. Modelo de argumento de Toulmin', onde: $\mathbf{D}=$ Dado; $\mathbf{J}$ = Justificativa; $\mathbf{B}=$ Conhecimento básico ("backing"); $\mathbf{Q}=$ Qualificador modal; $\mathbf{R}=$ Refutação; $\mathbf{C}=$ Conclusão

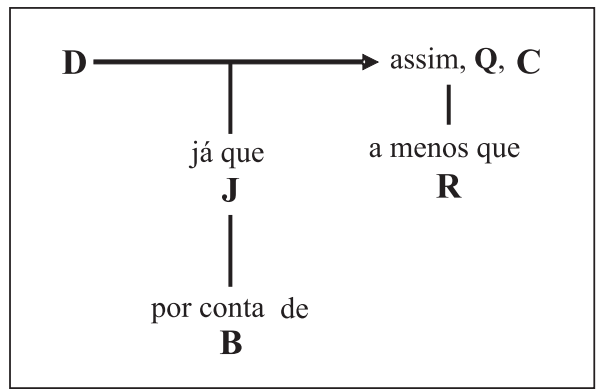

Os elementos fundamentais de um argumento são o dado (D), a conclusão (C) e a justificativa (J). É possível apresentar um argumento contando apenas com estes elementos, cuja estrutura básica é: "a partir de um dado $\mathbf{D}$, já que $\mathbf{J}$, então $\mathbf{C}$ ". Porém, para que um argumento seja completo pode-se especificar em que condições a justificativa apresentada é válida ou não, indicando um peso para tal justificativa. Assim, podem ser acrescentados ao argumento qualificadores modais $(\mathbf{Q})$, ou seja, especificações das condições necessárias para que uma dada justificativa seja válida. Da mesma forma, é possível especificar em que condições a justificativa não é válida ou suficiente para dar suporte à conclusão. Neste caso é apresentada uma refutação (R) da justificativa. Além dos elementos já citados, a justificativa, que apresenta um caráter hipotético, pode ser apoiada em uma alegação categórica baseada em uma lei, por exemplo. Trata-se de uma alegação que dá suporte à justificativa, denominada "backing" (B) ou conhecimento básico. O "backing" é uma garantia baseada em alguma autoridade, uma lei jurídica ou científica, por exemplo, que fundamenta a justificativa.

\section{Componentes do argumento, segundo Jiménez Aleixandre et al..$^{10}$}

Os autores propuseram a identificação dos componentes do argumento racional de Toulmin ${ }^{9}$ nas falas dos alunos, especificando os diferentes tipos de dados, afirmações ou enunciados que podem compor argumentos numa aula de ciências. O dado (D) pode ser caracterizado como um dado fornecido (DF) pelo professor, livro, texto, roteiro de experimento ou como um dado obtido (DO). Este último ainda é classificado como um dado empírico (DE), que pode proceder de uma experiência no laboratório, ou como dado hipotético (DH). Os enunciados são classificados em hipótese e conclusão. Os enunciados que questionam a validez de outro são denominados de oposição. Os demais componentes do argumento são interpretados como no modelo original.

\section{METODOLOGIA DE PESQUISA}

A proposta de ensino foi aplicada na disciplina SQF0321 Comunicação e Expressão em Linguagem Científica II, que prioriza o desenvolvimento de habilidades de comunicação em linguagem científica e é oferecida para alunos matriculados no segundo semestre do curso de Bacharelado em Química do Instituto de Química de São Paulo - Universidade de São Paulo.

A proposta em questão foi aplicada nos moldes descritos a seguir. No primeiro dia de aula do bimestre os alunos foram informados que as atividades do período envolveriam: o trabalho com casos investigativos; a preparação, em grupo, de uma apresentação oral sobre a resolução dos mesmos; a produção, em grupo, de um "diário do caso", que deveria deixar claro ao leitor o processo que os conduzira à resolução do caso, incluindo informações obtidas neste processo e reflexões sobre o seu andamento; a produção individual de um texto sobre o assunto envolvido no caso, com formato e linguagem direcionada a alunos do ensino médio.

Para que a proposta fosse colocada em prática fez-se necessária a produção dos casos, que foram elaborados de acordo com recomendações apontadas por Herreid ${ }^{17}$, sobre como se estruturar um "bom caso". Foram produzidos cinco casos, denominados Praga do Coqueiro, Caso das Próteses, Ameaça nos Laranjais, Poluição em Rondônia e Doença de Granja, com base em pesquisas divulgadas na revista Pesquisa FAPESP. Respectivamente, os artigos de divulgação que serviram de base para a elaboração de cada um dos casos foram: Feromônio controla praga do coqueiro (Revista Pesquisa FAPESP, n ${ }^{\circ}$ 93, p.62, 2003); Próteses de mamona (Revista Pesquisa FAPESP, n. ${ }^{\circ}$ 93, p.91, 2003); Risco de enfarto nos laranjais (Revista Pesquisa FAPESP, n 85, p.16, 2003); Mercúrio contamina índios em Rondônia (Revista Pesquisa FAPESP, $\mathrm{n}^{\circ}$ 89, p.30, 2003); Terapia genética para galinhas (Revista Pesquisa FAPESP, $\left.\mathrm{n}^{\circ} 78, \mathrm{p} .80,2002\right)$. O caso Praga do Coqueiro e o Caso das Próteses, aos quais nos referiremos no tópico Resultados e Discussão deste texto, encontram-se ilustrados, respectivamente, nos Quadros 2 e 3. O caso Ameaça nos Laranjais encontra-se ilustrado em artigo publicado nesta revista ${ }^{11}$ e os demais estão disponíveis na dissertação de mestrado de Sá $^{18}$.

No primeiro dia de aula foram também formados quinze grupos, sendo dez grupos de quatro alunos, quatro grupos de três alunos e um grupo de cinco alunos. Os casos foram distribuídos aleatoriamente, de modo que cada caso foi estudado por três grupos diferentes. Nesta ocasião os alunos foram orientados sobre possíveis maneiras de proceder para a resolução dos casos e passaram a utilizar o Guia para Análise e Resolução de Casos, que tinha como objetivo auxiliá-los na discussão e análise dos casos, e apresentava questões que deveriam ser solucionadas no decorrer dos estudos. A estrutura do guia assemelha-se àquela proposta por Waterman ${ }^{19}$ no trabalho Investigative Case Study Approach for Biology Learning e as questões foram elaboradas com base no modelo normativo de tomada de decisão de Kortland ${ }^{20}$, ilustrado no Quadro 4, que evidencia etapas capazes de facilitar a tomada de decisão pelos alunos com relação a um determinado assunto.

A observação do esquema apresentado no Quadro 4 permite concluir que, no modelo normativo de Kortland ${ }^{20}$, os critérios para avaliar as soluções alternativas (ou as características desejáveis de uma solução) são formulados em direta conexão com a identificação do problema. As soluções alternativas geradas são avaliadas em um estágio posterior de acordo com estes critérios, resultando em uma decisão sobre o que parece ser a melhor ou a pior solução. 
Quadro 2. Caso Praga do Coqueiro

Os pequenos agricultores da região litorânea do Estado de Alagoas sobrevivem basicamente da cultura do coco. No entanto, a exploração dessa importante fonte de divisas e de proteínas da população enfrenta um pequeno besouro, principal agente transmissor do nematóide responsável pela doença do anel vermelho, que mata o coqueiro e se espalha por toda a plantação.

Há algum tempo, o Sr. Francisco Freitas, proprietário da região onde a plantação de coqueiros está sendo ameaçada, tem enfrentado esse problema que compromete o meio de sobrevivência de muitos moradores da região. À noite, ao chegar em casa, resolve contar a sua filha o que está acontecendo, já que ela é estudante de Química na Universidade Federal de Alagoas, talvez possa lhe sugerir alguma solução para seu problema.

Ao sentarem para jantar Seu Francisco conversa com Isabel:

- Isabel, já tem algum tempo que a plantação de coqueiros não vai bem, isto está me preocupando muito. Semana passada o compadre Joaquim teve que vender a casa para pagar os trabalhadores e as outras dívidas que já vinham se acumulando há algum tempo, pois você sabe que a sua única fonte de renda vem desses coqueirais, desabafa o Sr. Francisco.

- O que está acontecendo na plantação do padrinho Joaquim?

- Não é só na dele. Todas as plantações da nossa região, até a minha, estão sofrendo com essas pragas que atingem os coqueirais e, se não cuidar, atacam toda a plantação. Foi isso que aconteceu com o compadre Joaquim. Como você é estudante de Química, pensei que talvez pudesse me ajudar a encontrar uma solução para esse problema, pois não sei mais o que fazer.

- Papai, não saberei lhe dar muitas informações sobre esse assunto. Mas não se preocupe, pois tenho alguns amigos que fazem parte do grupo de Ecologia Química e Comportamento de Insetos do Departamento de Química da UFAL. Falarei com eles e me informarei melhor.

À tarde, Isabel vai à universidade e procura o grupo:

- Olá colegas, estou precisando da ajuda de vocês. O problema é o seguinte: (Uma plantação de coqueiros está sendo atingida...). Após contar toda a história, Isabel fala:

- Gostaria de saber o que vocês podem fazer para nos ajudar.

- Nos últimos meses temos realizado algumas pesquisas sobre pragas que atingem a agricultura, iremos investigar o problema e veremos o que podemos fazer. Fala Alex, um dos integrantes do grupo.

- Muito obrigada! Contarei as novidades ao papai.

Vocês fazem parte desse grupo e lhes foi atribuída a missão de combater esse inimigo devastador, limitando seus danos e posteriormente providenciando a sua eliminação. Que medidas vocês irão tomar para resolver o problema que compromete a sobrevivência dos moradores daquela região?

Quadro 3. Caso das Próteses

João Carlos, 23 anos, há dois anos evita sair de casa para ir ao mercado, jogar com os amigos e até procurar emprego. Foi exatamente há dois anos que João foi vítima de um terrível acidente de moto, que acabou resultando em uma grande fratura no seu maxilar. A perda da antiga forma de seu rosto tornou-o uma pessoa triste, com baixa auto-estima e sem vontade de se relacionar com outras pessoas. Além disso, João sente dificuldades para falar e mastigar comidas sólidas.

João sempre morou em São Carlos, cursava Física na USP, mas abandonou o curso e outras atividades logo após o acidente.

Mariana, sua irmã, nunca desistiu de buscar uma solução para o problema de seu único irmão. Foi a hospitais, clínicas, falou com vários médicos, mas a situação era difícil, pois não tinham muitos recursos financeiros. No entanto, depois de várias tentativas frustradas, Mariana conversa com um médico que se mostra disposto a ajudá-la.

Mariana chega em casa eufórica e conversa com os familiares:

- Mamãe, João, venham aqui. Tenho ótimas notícias para vocês.

- O que aconteceu? Pergunta João, sem mostrar muito entusiasmo.

- Dr. Alberto mostrou-se muito interessado em nos ajudar. Falou sobre vários tipos de próteses que estão sendo utilizadas em pessoas vítimas de acidentes com armas, carros e também tumores. Essas próteses substituem ossos da mandíbula, crânio ou face.

- Mas, como iremos pagar uma cirurgia como essa? Deve custar muito caro, comenta Dona Lourdes, sua mãe. 
Quadro 3. continuação

- Dr. Alberto falou que cirurgias como essas podem ser feitas com custos não muito elevados e prometeu falar com alguns amigos seus, especialistas nessa área e, junto com eles, pensar em um tipo de prótese adequada para João.

- Obrigado minha irmã. Meu maior sonho é ter de volta a antiga forma do meu rosto.

Dois dias depois, Dr. Alberto liga para Mariana:

- Olá Mariana, tenho ótimas notícias. Conversei com alguns colegas e eles me falaram sobre excelentes próteses, que estão sendo utilizadas atualmente, e que irão decidir sobre o tipo mais adequado a ser usado para o caso de João. Falei da situação de seu irmão e eles estão dispostos a operá-lo o mais breve possível. É preciso que ele compareça a uma consulta amanhã às dez horas para acertarmos tudo.

- Muito obrigada, Dr Alberto. Amanhã estaremos lá.

No dia seguinte, tudo foi acertado e a cirurgia marcada para uma semana depois.

Vocês, como estudantes de Química, ajudarão a equipe de médicos a escolher o tipo de prótese mais adequado para o caso de João Carlos.

Quadro 4. Modelo normativo do processo de tomada de decisão de Kortland ${ }^{20}$.

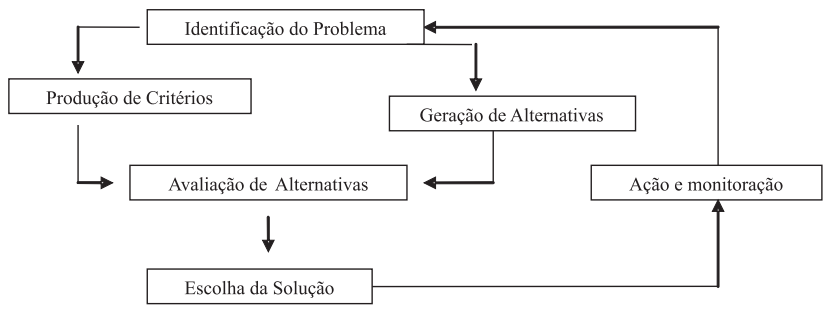

Finalmente, estes critérios são usados para monitorar os efeitos da decisão tomada: a solução escolhida teve os efeitos desejados na prática? Assim, este modelo tem como um dos seus principais objetivos ensinar os estudantes a tomarem decisões independentemente e de maneira reflexiva, comparando sistematicamente os prós e contras das possíveis alternativas de solução.

Durante o bimestre foram reservados momentos para que os alunos falassem sobre o desenvolvimento das atividades na busca para resolução dos casos e sanassem suas eventuais dúvidas. Também foram estabelecidos horários de monitoria semanais, com duas horas de duração. Na última semana do bimestre foi organizado um mini-simpósio, realizado em horário extraclasse, durante um intervalo de quatro dias, totalizando sete horas e meia de duração, sendo uma hora e trinta min para cada um dos horários reservados. Neste mini-simpósio foram apresentadas as resoluções dos casos por um dos membros de cada grupo, em um intervalo de 15 a 20 min. A programação do mini-simpósio foi elaborada de tal forma que três casos diferentes foram apresentados em cada noite. Ou seja, em nenhuma das ocasiões verificou-se a apresentação da resolução de casos idênticos. O membro do grupo responsável por apresentar oralmente a resolução do caso era sorteado quinze minutos antes do início da apresentação. Esperava-se, com isso, garantir que todos os integrantes da equipe estivessem devidamente preparados para apresentar seus argumentos sobre a resolução escolhida para o caso. Cabe ainda esclarecer que os alunos foram convidados a assistir a todas as apresentações do mini-simpósio, tendo, no entanto, que comparecer, obrigatoriamente, apenas àquelas apresentações programadas para o mesmo período reservado para o seu grupo.
Em todos os dias do mini-simpósio, após a apresentação da resolução de cada um dos casos, a professora solicitou aos demais grupos presentes que procurassem sanar suas dúvidas e que fizessem questionamentos com relação à pertinência da alternativa apontada pela equipe expositora como a melhor solução para o caso. Ao final das apresentações, cada grupo de alunos foi também indagado a respeito de suas impressões e de possíveis sugestões em relação à atividade realizada.

Para a aplicação da proposta foram utilizadas aproximadamente dez horas em sala de aula (horário normal), sendo que a maior parte deste tempo foi destinada a discussões realizadas em grupo pelos alunos e à resolução de questões relacionadas aos casos. Para a realização do mini-simpósio foram necessárias sete horas e meia de atividades fora do horário normal de aula. No entanto, cada um dos alunos teve que comparecer a apenas uma hora e meia do minisimpósio, uma vez que tinham a obrigação de participar somente daquelas apresentações programadas para o mesmo período reservado para o seu grupo. Ou seja, os alunos dedicaram onze horas e meia para as atividades realizadas em sala de aula. Porém, acreditamos que um tempo considerável tenha sido utilizado pelos alunos em atividades extraclasse (buscas por informações para resolução dos casos, preparação do "diário do caso", redação de textos, preparação das apresentações orais etc).

Foram tomados como sujeitos da pesquisa 58 alunos, matriculados na disciplina. No entanto, apenas 57 alunos cumpriram todas as etapas da proposta de ensino, pois um deles desistiu de cursar a disciplina no decorrer do semestre. A coleta de dados foi realizada por meio dos seguintes procedimentos: (a) filmagem em fitas VHS das aulas nas quais as resoluções dos casos foram apresentadas (minisimpósios): as apresentações orais dos alunos sobre a resolução dos casos, a posterior discussão realizada sobre a pertinência da solução encontrada para cada um dos casos e a apresentação das impressões/ sugestões dos membros de cada grupo sobre a atividade realizada foram filmadas; (b) solicitação de trabalhos escritos aos alunos, relacionados à resolução do caso: as respostas às questões elaboradas com base no modelo de Kortland ${ }^{20}$, o "diário do caso" e o texto produzido foram reunidos e parte deste material foi analisada; (c) aplicação de questionário sobre as percepções individuais dos alunos a respeito das habilidades adquiridas com o desenvolvimento da atividade: as respostas dos alunos ao questionário foram reunidas, categorizadas e analisadas. 
Para verificar em que medida a proposta foi capaz de estimular a elaboração de argumentos por parte dos alunos e avaliar a qualidade dos argumentos por eles apresentados na resolução dos casos nos valemos das transcrições das falas dos alunos durante a apresentação e discussão da resolução dos casos e da análise dos conteúdos presentes nos "diários dos casos". Algumas das conclusões decorrentes da análise dos demais dados coletados encontram-se publicadas na revista Enseñanza de las Ciencias $^{13}$ e nas atas do $V$ Encontro Nacional de Pesquisa em Educação em Ciências ${ }^{21}$.

\section{RESULTADOS E DISCUSSÃO}

Neste trabalho aplicamos uma proposta de ensino pautada no método de Estudo de $\mathrm{Caso}^{8}$, que visou estimular a elaboração de argumentos por parte dos alunos e avaliar a qualidade dos argumentos apresentados na resolução dos casos.

Os alunos trabalharam em grupo e, ao final do processo, foram organizadas apresentações orais, nas quais um integrante de cada grupo propôs uma resolução para o caso. Cada caso foi estudado por três grupos diferentes de alunos. Os argumentos apresentados para justificar a escolha feita por cada um dos grupos para a resolução do caso foram analisados segundo o modelo de Toulmin na adaptação de Jiménez Aleixandre et al. ${ }^{10}$.

Considerando as observações de Driver e Newton ${ }^{22}$ sobre a necessidade de incorporar o conhecimento específico do assunto à análise dos argumentos (uma vez que o esquema de Toulmin ${ }^{9}$ é útil para se verificar a estrutura do argumento, mas não a sua validez), levamos também em conta este tipo de conhecimento na análise dos argumentos produzidos pelos estudantes. As informações contidas no "diário do caso" de cada um dos grupos foram de grande valia na determinação da adequação dos conhecimentos específicos apresentados para a resolução dos casos. No entanto, para a realização de algumas análises também se fizeram necessárias consultas a outras fontes de informação.

A seguir apresentamos a análise dos argumentos dos estudantes, com o intuito de avaliar a qualidade dos mesmos. À semelhança do que tem sido feito por alguns autores ${ }^{15,23}$, consideramos, para todos os casos, nesta análise: a forma como os estudantes relacionaram os diferentes componentes do argumento; o estabelecimento de justificativas para chegar às conclusões; se estas justificativas se apoiavam em conhecimento básico ou não; a utilização de qualificadores e refutações durante a apresentação de argumentos.

Não apresentaremos aqui a análise detalhada que foi realizada para cada um dos casos e que se encontra na ref. 18. Este tipo de análise será apresentado apenas para dois casos (Caso Praga do Coqueiro e Caso das Próteses). No entanto, uma análise global comparativa sobre os componentes dos argumentos presentes em cada um dos casos solucionados será também realizada.

\section{Componentes dos argumentos identificados na apresentação oral sobre a resolução do Caso Praga do Coqueiro}

O caso denominado Praga do Coqueiro colocava os estudantes a par de uma praga que estava atacando os coqueiros de uma região litorânea do Estado de Alagoas, no Nordeste Brasileiro (Quadro 2). A doença nos coqueirais havia sido desencadeada pela ação de um besouro, principal agente transmissor do nematóide responsável pela doença do anel vermelho, que matava os coqueiros e se espalhava por toda a plantação, ameaçando a principal fonte de renda dos moradores da região. Como estudantes de química, cabia aos membros dos três grupos responsáveis pela resolução desse caso a missão de investigar o problema, procurar possíveis alternativas de solução, apontar uma delas como sendo a mais viável e argumentar a favor da mesma.
Os grupos G1, G2 e G3 incumbidos de resolver o caso concluíram que o uso do feromônio rincoforol era uma solução viável para o problema. No entanto, o grupo G2 aliou a Técnica do Inseto Estéril (TIE) ao uso do rincoforol e o grupo G3 chamou a atenção para a questão da necessidade de conscientização dos produtores. Assim, as diferenças encontradas na forma como os grupos resolveram o caso sugerem que cada um deles procurou, de maneira independente, alternativas para o problema.

Do ponto de vista estrutural, verificamos que os três grupos fizeram uso de dados fornecidos que fundamentaram suas conclusões. Nenhum dado empírico foi identificado nos argumentos dos grupos. Também verificamos que os grupos fizeram uso de justificativas, que permitiam passar dos dados para conclusão final. Apenas os grupos G1 e G3 apresentaram conhecimentos básicos, que atuaram como suporte para as suas justificativas. Uma refutação foi identificada nos argumentos do grupo G2, quando foi apresentada uma condição excepcional em que as justificativas por eles empregadas não eram válidas ou suficientes para dar suporte à conclusão de que o rincoforol era uma medida única e absoluta para resolver o caso. Ou seja, a partir das justificativas apresentadas, o grupo concluiu que o rincoforol era uma boa medida, a menos que fosse para ser usado em larga escala, o que acarretaria no aumento do custo para os produtores. Devido a esta refutação, o grupo chegou à segunda conclusão, de que era conveniente associar o feromônio rincoforol à TIE. Nenhum tipo de qualificador foi identificado nos argumentos dos grupos G1, G2 e G3.

Quanto às fontes de pesquisa anexadas aos "diários dos casos" observamos que, com exceção do grupo G3, todos os grupos buscaram artigos científicos para auxiliá-los na empreitada de solucionar o caso. Para tanto recorreram a sites de busca como o Google e bases de dados eletrônicas como o Scielo e Web of Science. No diário do grupo G2 constavam ainda recortes de reportagens extraídas de sites relacionados à Empresa Brasileira de Pesquisa Agropecuária (Embrapa), à Sociedade Brasileira para o Progresso da Ciência (SBPC) etc. Também foi relatado o envio de e-mails para o docente responsável pelo Grupo de Ecologia Química e Comportamento de Insetos, da Universidade Federal de Alagoas (UFAL), solicitando informações sobre a doença do anel vermelho, e para pesquisadores do Centro de Energia Nuclear na Agricultura (CENA), procurando informações sobre a TIE. O grupo obteve resposta de alguns pesquisadores, tendo sido os e-mails, anexados ao diário. Além disso, o grupo G2 também recorreu a conversas com um professor do Grupo de Química Ambiental do próprio Instituto de Química de São Carlos. Não foi possível identificar no "diário do caso" produzido pelo grupo G3 as fontes de pesquisa utilizadas para a resolução do caso. Porém, as referências bibliográficas, citadas nos slides utilizados na apresentação oral, sugerem que o grupo buscou informações somente em sites na internet. Nenhuma referência à utilização de fontes primárias foi feita pela equipe.

Com relação ao conteúdo dos argumentos apresentados pelos grupos, constatamos que os dados fornecidos e as justificativas utilizadas eram condizentes com informações contidas em artigos científicos. No entanto, com relação à refutação colocada pelo grupo G2, verificamos uma pequena discordância de informações. De acordo com os artigos, o uso do feromônio traz considerável economia para o agricultor e tem sido sintetizado e distribuído pelo Grupo de Ecologia Química da UFAL. Não encontramos nenhuma referência sobre desvantagens econômicas associadas à utilização em larga escala deste produto.

Componentes dos argumentos identificados na apresentação oral sobre a resolução do Caso das Próteses

O caso denominado Caso das Próteses trata da situação de um 
jovem chamado João Carlos, vítima de um grave acidente de moto, que provocou uma grande fratura no seu maxilar (Quadro 3). As sequielas causadas pelo acidente fizeram com que o rapaz se tornasse uma pessoa triste, desmotivada e com dificuldades de se relacionar com as outras pessoas. Além disso, o jovem ficou com dificuldades para falar e mastigar comidas sólidas. A situação de João Carlos é complicada, pois a família não dispõe de recursos financeiros suficientes para busca de tratamento particular. Como futuros químicos, cabia aos grupos responsáveis pela resolução desse caso ajudar a equipe de médicos a escolher o tipo de prótese mais adequado para o caso de João Carlos.

A partir da análise dos argumentos produzidos pelos grupos G4, G5 e G6 verificamos que os três grupos estruturaram de forma adequada os seus argumentos. Todos fizeram uso de dados fornecidos, que serviram de fundamento para a conclusão, que foi comum aos três grupos, de que a opção mais viável era o uso da prótese de mamona. Cabe ainda ressaltar que, apesar dos grupos terem chegado à mesma conclusão, as informações contidas nos "diários dos casos" demonstram os diferentes caminhos percorridos por cada um deles para alcançá-la.

Todos os grupos apresentaram justificativas para o fato da prótese de mamona ser a mais indicada para o caso e recorreram a conhecimentos básicos, que serviram de suporte para as respectivas justificativas. Com o objetivo de qualificar sua conclusão, o grupo G4 inseriu também um qualificador modal na argumentação, que consistiu no uso do advérbio "certamente" diante da conclusão, com o intuito de indicar a força conferida pelas justificativas apresentadas. Nenhuma refutação foi identificada nos argumentos dos grupos G4, G5 e G6.

Quanto ao conteúdo apresentado para fundamentar a argumentação dos alunos, todos os grupos forneceram informações fidedignas sobre questões relacionadas às próteses, de acordo com dados relatados na literatura. No que diz respeito às fontes de pesquisa utilizadas, a análise dos "diários dos casos" nos permitiu verificar o empenho dos grupos na busca de informações confiáveis para compreensão e resolução dos casos. Quanto às fontes de pesquisa utilizadas pelo grupo $\mathrm{G} 4$, verificamos que constavam no "diário do caso" vários materiais usados na investigação do problema. O primeiro material citado foi um livro da área de odontologia, que trata da questão de implantes. Algumas páginas do livro foram copiadas e anexadas ao diário. Artigos científicos e recortes de reportagens extraídas da internet também foram anexados. O grupo relatou ainda o envio de e-mails para docentes, da área de odontologia, e a procura pelo professor responsável pela criação da prótese da mamona. Durante a conversa com este professor, os alunos coletaram mais reportagens, artigos e depoimentos sobre o assunto. $\mathrm{O}$ professor ainda mostrou fotos e materiais sintetizados a partir do polímero e forneceu uma pequena amostra de um material, que o grupo usou como ilustração no diário.

O grupo G5 não recorreu a livros ou artigos científicos para resolução do caso. Diversos sites da internet foram consultados e todos os endereços eletrônicos foram citados no diário. Durante as atividades, um dos alunos entrou em contato com um professor do Curso de Odontologia da Universidade de Ribeirão Preto (UNAERP) que se prontificou a ajudar o grupo nos procedimentos necessários para a resolução do caso e enviou também um receituário aos estudantes, que foi anexado ao diário. Os alunos deste grupo também recorreram a entrevistas com o professor responsável pela criação da prótese da mamona, que cedeu ao grupo imagens de cirurgias de implante de próteses. A entrevista com o professor foi gravada em uma fita cassete, que foi anexada ao "diário do caso".

Com relação às fontes de pesquisa utilizadas pelo grupo G6, verificamos a existência de diversas reportagens sobre o assunto, todas extraídas de sites da internet e anexadas ao diário. Nenhuma referência à utilização de artigo científico foi feita. $\mathrm{O}$ grupo também procurou um docente para esclarecimentos sobre o assunto, que explicou todo o processo envolvido na produção da prótese de mamona. Contato com outros profissionais da área foi buscado, sem sucesso.

\section{Componentes dos argumentos em todos os casos solu- cionados: uma análise comparativa}

Alguns estudos relatados na literatura buscam mecanismos capazes de fornecer indícios quanto à qualidade dos argumentos produzidos pelos alunos em cursos de ciências. Jiménez Aleixandre e Bustamante $^{4}$ consideram de boa qualidade os argumentos que são acompanhados de justificativas. Nesta perspectiva, os argumentos produzidos pelos alunos na resolução dos casos propostos podem ser considerados de boa qualidade, uma vez que todos eles foram acompanhados de justificativas.

$\mathrm{Na}$ metodologia proposta por Erduran et al. ${ }^{23}$ a qualidade dos argumentos é avaliada a partir da observação da combinação dos componentes do argumento, segundo Toulmin ${ }^{9}$, nas falas dos alunos. Ou seja, as combinações que possuem um maior número de componentes são típicas de um argumento mais bem elaborado. Os autores assumem que, um argumento que possua "conclusãodado-justificativa" é menos sofisticado que um argumento que tenha "conclusão-dado-justificativa-refutação". Desta maneira, sugerem combinações dupla, tripla, quádrupla ou quíntupla de componentes, como indicativas de ordem crescente de complexidade do argumento. Por exemplo: CD (conclusão-dado); CJ (conclusãojustificativa); CDJ (conclusão-dado-justificativa); CDB (conclusãodado-"backing"); CDR (conclusão-dado-refutação); CDJB (conclusão-dado-justificativa-“backing”); CDJR (conclusão-dado-justificativa-refutação); CDJQ (conclusão-dado-justificativaqualificador); CDJBQ (conclusão-dado-justificativa-"backing”qualificador). Estas combinações do Toulmin's Argument Pattern (TAP) servem, portanto, para indicar a qualidade da argumentação dos alunos.

$\mathrm{Na}$ análise da qualidade dos argumentos apresentados pelos alunos para solucionar os casos, adotamos a metodologia proposta por Erduran et al. ${ }^{23} \mathrm{e}$ observamos as tendências nos discursos dos grupos, segundo a distribuição no TAP. Os dados obtidos, relativos aos argumentos produzidos na resolução dos cinco casos, encontram-se sumarizados na Figura 1. O eixo $x$ indica as características do TAP que foram usadas pelos alunos em diferentes combinações. O eixo $y$ ilustra o número de vezes que cada combinação do TAP ocorreu no discurso dos alunos. Ou seja, o gráfico indica o número de vezes que cada argumento foi formulado em termos de combinações características do TAP.

Como podemos observar na Figura 1, cinco tipos de combinações das características do TAP foram identificados nos discursos dos alunos durante as apresentações dos casos, em diferentes freqüências. Verificamos que a combinação do tipo "conclusão-dadojustificativa" (CDJ) foi usada pelos grupos em uma frequiência de 7 vezes e a combinação do tipo "conclusão-dado-justificativabacking" (CDJB), em que um conhecimento básico é adicionado à argumentação com o objetivo de fundamentar a justificativa, foi encontrada em uma freqüência de 8 vezes. Estes números sugerem a habilidade dos alunos em utilizarem os elementos, que segundo Toulmin" ${ }^{9}$, são fundamentais na composição de um argumento, e em recorrerem a uma combinação um pouco mais complexa quando possuem informações que servem de suporte para as justificativas apresentadas. Em contrapartida, combinações do tipo "conclusão-dado-justificativa-refutação" (CDJR) e "conclusão-dado-jus- 


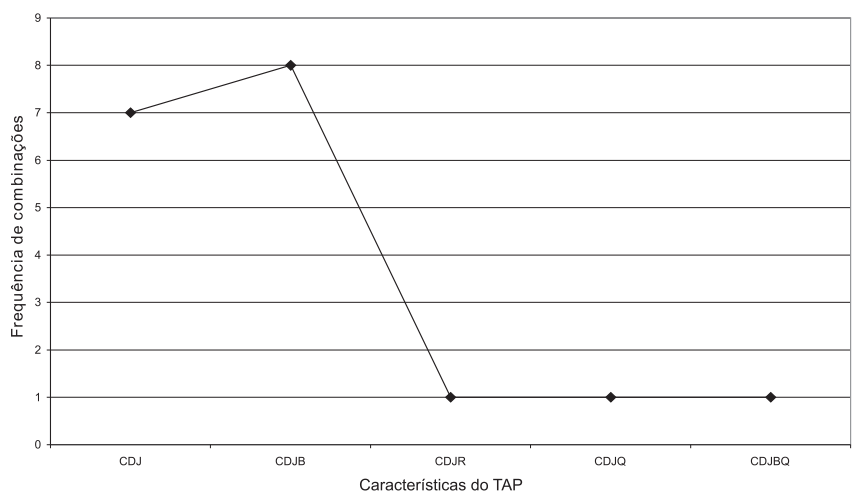

Figura 1. Freqüência do TAP nos argumentos produzidos pelos alunos na resolução dos cinco casos, onde: $\boldsymbol{C D J}=$ Conclusão-dado-justificativa; $\boldsymbol{C D J B}$ = Conclusão-dado-justificativa-backing; $\boldsymbol{C D J R}=$ Conclusão-dadojustificativa-refutação; $\mathbf{C D J Q}=$ Conclusão-dado-justificativa-qualificador modal; $\boldsymbol{C D J B Q}=$ Conclusão-dado-justificativa-backing-qualificador modal

tificativa-qualificador" (CDJQ) também foram identificadas nos discursos dos alunos, no entanto, apenas uma vez, cada uma delas. A única combinação composta por cinco elementos foi a do tipo “conclusão-dado-justificativa-backing-qualificador" (CDJBQ), identificada apenas uma vez no discurso dos alunos. A pouca ocorrência destas combinações provavelmente relaciona-se às dificuldades dos alunos em inserir elementos como refutações e qualificadores modais em seus argumentos.

Com o intuito de averiguarmos o quanto cada um dos casos elaborados estimulou determinados tipos de combinações do TAP nos argumentos dos alunos durante as apresentações orais sobre a resolução dos casos, analisamos a quantidade de vezes que cada uma das combinações apareceu na resolução de cada caso (Figura 2).

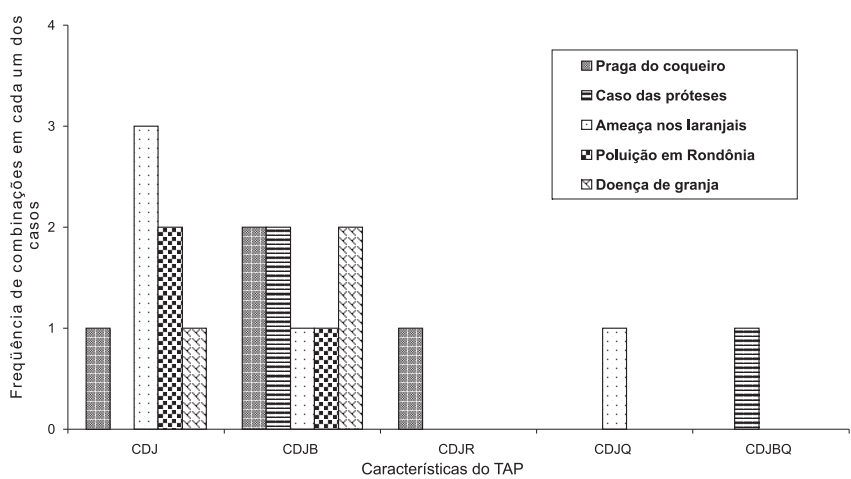

Figura 2. Freqüência do TAP em relação a cada um dos casos solucionados pelos alunos, onde: $\boldsymbol{C D J}=$ Conclusão-dado-justificativa $; \boldsymbol{C D J B}=$ Conclusão-dado-justificativa-backing; CDJR = Conclusão-dadojustificativa-refutação; $\mathbf{C D J Q}=$ Conclusão-dado-justificativa-qualificador modal; $\boldsymbol{C D J B Q}=$ Conclusão-dado-justificativa-backing-qualificador modal

A partir da análise da Figura 2, observamos que o caso Praga do Coqueiro estimulou a elaboração de três tipos distintos de combinações do TAP, sendo que uma das combinações, a do tipo CDJB, foi identificada duas vezes no discurso dos alunos que ficaram responsáveis pela resolução do caso. Foi o único caso em que foi identificada a combinação do tipo CDJR. Este foi um dos casos em que os estudantes demonstraram maior desenvoltura para sua resolução. Isto pode ser devido ao grande número de pesquisas existentes sobre o assunto e a grande variedade de alternativas de soluções encontradas para o caso, que permitiu que os alunos pudessem avaliar a questão com maior profundidade e sem grandes empecilhos.

No que diz respeito ao Caso das Próteses verificamos nos argumentos estruturados pelos grupos responsáveis pela resolução deste caso, a presença de apenas dois tipos de combinações do TAP. Uma delas é a do tipo CDJB, que aparece por duas vezes nas falas dos alunos, e a outra é a CDJBQ, combinação mais complexa dentre as identificadas nos discursos dos grupos. A maior complexidade nos argumentos dos estudantes que resolveram este caso pode estar relacionada ao grande número de informações que lhes foi fornecido, inclusive por pesquisadores diretamente envolvidos na questão abordada no caso que, além de informações, também forneceram imagens e amostras de material relacionadas à questão das próteses. Tais acontecimentos, provavelmente, estimularam a criatividade destes alunos, fato constatado a partir da forma como as resoluções do caso foram apresentadas e pelos argumentos fornecidos pelos grupos.

Três diferentes tipos de combinações foram identificados nas apresentações dos grupos incumbidos de solucionar o caso Ameaça nos Laranjais. Uma delas, a do tipo CDJ, aparece por três vezes nos discursos dos grupos, as do tipo CDJB e CDJQ aparecem uma única vez. Foi o único caso em que foi identificada a combinação do tipo CDJQ. Os grupos responsáveis pela resolução do caso não demonstraram dificuldades em solucioná-lo.

O caso Poluição em Rondônia foi o caso que, de acordo com os alunos, apresentou maiores dificuldades de resolução, devido à complexidade envolvida no problema. Todos os grupos responsáveis pela resolução do caso alegaram a ausência de soluções viáveis para sua resolução. Possivelmente, esta é a razão pela qual os grupos tiveram dificuldades em estruturar argumentos mais complexos. $\mathrm{Na}$ análise do discurso dos grupos que resolveram esse caso, a combinação do tipo CDJ aparece por duas vezes, e a do tipo CDJB aparece uma única vez nas falas dos estudantes.

Nas apresentações orais sobre o caso Doença de Granja foram identificados dois tipos de combinações: a do tipo CDJ e a do tipo CDJB. A primeira aparece apenas uma única vez, enquanto que a segunda é verificada por duas vezes nas falas dos alunos. Os grupos que resolveram este caso, apesar de seus argumentos não apresentarem grande complexidade, demonstraram desenvoltura na exposição das suas idéias.

\section{CONSIDERAÇÕES FINAIS}

A necessidade do desenvolvimento da capacidade argumentativa dos alunos em cursos de ciências tem sido discutida nos últimos $\operatorname{anos}^{16,23}$. Neste sentido, elaboramos e aplicamos uma proposta de ensino na qual estudantes de graduação em química solucionaram casos investigativos de caráter sócio-científico e, após uma série de atividades realizadas durante um bimestre, apresentaram oralmente as resoluções dos casos e argumentaram sobre a sua pertinência. A identificação dos componentes do argumento, segundo o modelo de Toulmin ${ }^{9}$, presentes nas falas dos alunos, não foi uma tarefa fácil. Este tipo de dificuldade tem sido apontado por vários pesquisadores que se mobilizaram para fazer a análise da argumentação de estudantes com base neste modelo e relataram que, em algumas situações, é difícil distinguir entre "dados" e "justificativas" ou "justificativas" e "conhecimentos básicos", por exemplo $^{16,23}$. No nosso trabalho também encontramos dificuldades na distinção entre alguns elementos.

A partir da análise dos argumentos dos alunos, constatamos que a natureza do caso, aparentemente, dificultou ou facilitou a sua resolução e elaboração de argumentos pelos grupos. Como exemplo, podemos citar o caso Poluição em Rondônia, sobre o qual 
os estudantes alegaram a ausência de soluções viáveis para o problema. Como consequiência da escassez de alternativas, a maioria dos argumentos apresentados continha apenas três componentes do TAP (CDJ). Em contrapartida, a estrutura dos argumentos produzidos pelos grupos responsáveis pela resolução do Caso das Próteses foi bem mais complexa, apresentando quatro (CDJB) ou cinco componentes do TAP (CDJBQ), fato que pode estar relacionado às diversas alternativas de solução existentes para o caso e ao fácil acesso a diversas informações a respeito do assunto.

A natureza do caso a ser solucionado pode ainda favorecer, ou não, a incorporação de questões éticas e ambientais ao discurso argumentativo dos estudantes. Verificamos a incorporação mais efetiva de questões de tal natureza no discurso dos alunos responsáveis pela resolução do caso Poluição em Rondônia, que envolvia aspectos sócio-científicos mais amplos que os demais. Assim, além de conduzir o grupo à busca de informações que suportassem uma argumentação de caráter técnico, o caso favoreceu a discussão sobre aspectos valorativos, culturais e éticos. Seguramente, a proposta de resolução de casos com características similares às do caso Poluição em Rondônia vai ao encontro, mais efetivamente, das considerações de Santos e Mortimer ${ }^{24}$ sobre o fato de que na abordagem curricular para o desenvolvimento da capacidade de tomada de decisão, esta não deve ser guiada somente por "aspectos técnicos que indicam o caminho da opção a seguir".

Levando em conta a metodologia proposta por Erduran et al. ${ }^{23}$ para análise da qualidade dos argumentos, verificamos a boa qualidade dos argumentos apresentados pelos grupos. No entanto, acreditamos que embora a atividade proposta tenha atingido o objetivo de estimular a elaboração de argumentos por parte dos alunos, e que os argumentos produzidos possam ser considerados de boa qualidade, o estudo aqui descrito aponta para uma outra necessidade, que já vem sendo atendida em alguns países ${ }^{3,25}$ e que, até onde vai o nosso conhecimento, não está sendo considerada em cursos de ciências no Brasil: é preciso ensinar aos alunos a arte da argumentação, apresentando para eles os componentes do argumento e desenvolvendo estratégias que os levem à produção de bons argumentos.

Com relação aos tipos de dados empregados pelos estudantes, o dado fornecido foi o mais mencionado, o que não é surpreendente, uma vez que todas as informações por eles apresentadas eram provenientes de artigos científicos, livros, sites da internet e entrevistas com profissionais da área científica. Não houve relato de nenhuma experiência realizada em laboratórios e nenhum dado oriundo de observações feitas pelos próprios alunos. Por esta razão, dados empíricos não foram identificados na argumentação dos grupos.

De maneira geral, verificamos que as informações fornecidas pelos grupos estavam fundamentadas em colocações presentes em artigos científicos ou em outras fontes fidedignas. Porém, alguns pequenos equívocos, como confusões com relação aos nomes dos personagens dos casos e ao local de ocorrência dos mesmos, foram identificados nas apresentações de alguns grupos. Cabe esclarecer que, baseados na observação do desempenho dos grupos, acreditamos que tais equívocos estão mais relacionados a uma certa displicência que à falta de conhecimento a respeito do assunto.
Considerando os esforços envidados na resolução dos casos, acreditamos que a proposta de ensino teve uma boa receptividade junto aos alunos e se mostrou adequada para desenvolver a capacidade argumentativa dos mesmos, além de proporcionar o desenvolvimento de outras habilidades, de caráter formativo, como comunicação oral e escrita, trabalho em grupo, tomada de decisão e senso crítico.

\section{MATERIAL SUPLEMENTAR}

Os Esquemas que ilustram os componentes dos argumentos usados pelos alunos durante as apresentações orais sobre as resoluções dos casos encontram-se disponíveis gratuitamente em http:// quimicanova.sbq.org.br, na forma de arquivo PDF.

\section{AGRADECIMENTOS}

Ao CNPq e à FAPESP (Processo $n^{\circ}$ 05/54035-3) pelo apoio financeiro e aos alunos matriculados na disciplina SQF321 do IQSC - USP no segundo semestre letivo de 2004.

\section{REFERÊNCIAS}

1. Mortimer, E. F.; Linguagem e formação de conceitos no ensino de ciências, Ed. da UFMG: Belo Horizonte 2000.

2. Almeida, M. J. P. M.; Discursos da ciência e da escola: ideologia e leituras possíveis, Mercado de Letras: Campinas 2004.

3. Jorge, A. S.; Puig, N. S.; Enseñanza de las Ciencias 2000, 18, 405.

4. Jiménez Aleixandre, M. P.; Bustamante, J. D.; Enseñanza de las Ciencias $\mathbf{2 0 0 3}, 21,359$.

5. Sanmartí, N.; Aprendre ciències tot aprenent a escriure ciència, Centre de Recursos Pedagògics de la Ciutat de Barcelona: Barcelona, 2003.

6. Driver, R.; Newton, P.; Osborne, J.; Science Education 2000, 84, 287.

7. Santos, W. P.; Mortimer, E. F.; Scott, P. H.; Revista Brasileira de Pesquisa em Educação em Ciências 2001, 1, 140.

8. Herreid, C. F.; J. Coll. Sci. Teach. 1994, 23, 221.

9. Toulmin, S.; The uses of argument, University Press: Cambridge, 1958.

10. Jiménez Aleixandre, M. P.; Castro, C. R.; Pérez, V. A.; Atas do VI Encontro de Pesquisa em Ensino de Física, Florianópolis, Brasil, 1998.

11. Sá, L. P.; Francisco, C. A.; Queiroz, S. L.; Quim. Nova 2007, 30, 731.

12. http://www.if.ufrgs.br/public/ensino/vol5/n3/v5_n3_a2.htm>, acessada em Novembro 2005.

13. http://www.blues.uab.es/ sice23, acessada em Novembro 2006.

14. Jiménez Aleixandre, M. P.; Rodríguez. B.; Duschl, R. A.; Science Education 2000, 84, 757.

15. Villani, C. E. P.; Nascimento, S. S.; Investigações em Ensino de Ciências 2003, 8, 1 .

16. Kelly, G. J.; Takao, A.; Science Education 2002, 86, 314.

17. Herreid, C. F.; J. Coll. Sci. Teach. 1998, 27, 163.

18. Sá, L. P.; Dissertação de Mestrado, Universidade de São Paulo, Brasil, 2006

19. Waterman, M. A.; Bioscene - Journal of College Biology Teaching 1998, 24,3 .

20. Kortland, K.; Science Education 1996, 80, 673.

21. Sá, L. P.; Queiroz, S. L.; Atas do V Encontro Nacional de Pesquisa em Educação em Ciências, Bauru, Brasil, 2005.

22. Driver, R.; Newton, P.; Resumos da European Science Education Research Association Conference, Italia, Roma, 1997.

23. Erduran, S.; Simon, S.; Osborne, J.; Science Education 2004, 88, 915.

24. Santos, W. L. P.; Mortimer, E. F.; Ciência \& Educação 2001, 7, 95.

25. Zohar, A.; Nemet, F.; J. Res. Sci. Teach. 2002, 39, 35. 


\section{PROMOVENDO A ARGUMENTAÇÃO NO ENSINO SUPERIOR DE QUÍMICA}

\section{Luciana Passos Sá}

Departamento de Química, Universidade Federal de São Carlos, CP 676, 13565-905 São Carlos - SP, Brasil

Salete Linhares Queiroz*

Instituto de Química de São Carlos, Universidade de São Paulo, CP 780, 13560-970 São Carlos - SP, Brasil

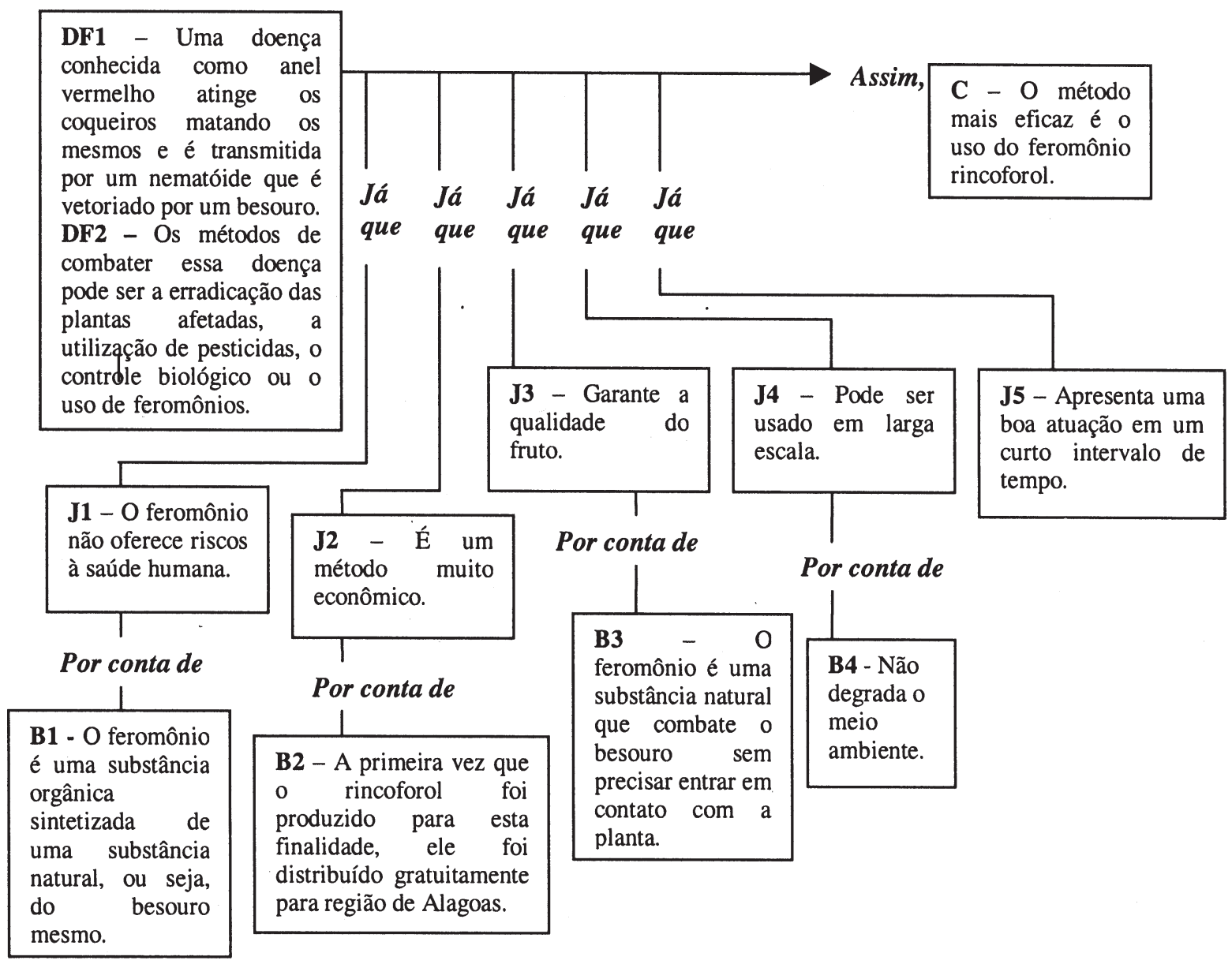

Esquema $1 S$ - Argumentos apresentados pelo grupo G1 para a resolução do caso Praga do Coqueiro 
(a)

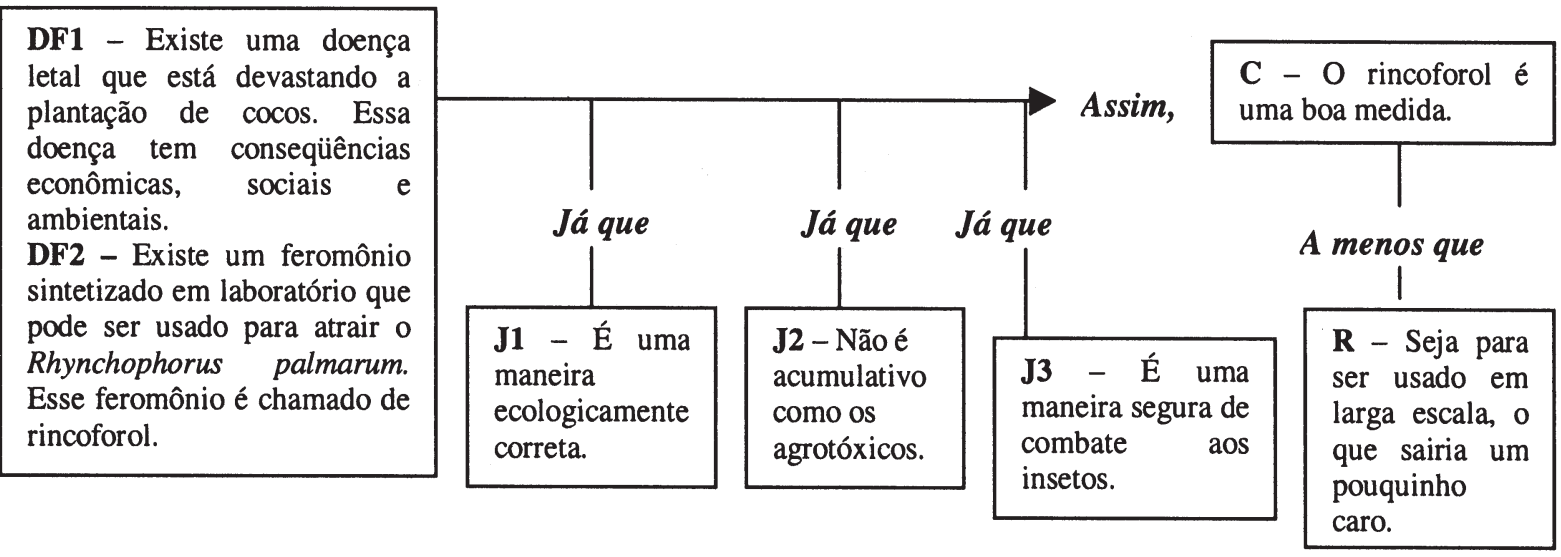

(b)

$\begin{aligned} & \text { D - A Técnica do Inseto } \\
& \text { Estéril (TIE) consiste em } \\
& \text { tornar os insetos estéreis, de } \\
& \text { forma que eles não se } \\
& \text { reproduzam mais. }\end{aligned} \mid$ Assim, \begin{tabular}{l} 
C- $\begin{array}{l}\text { Então vamos } \\
\text { associar a técnica do } \\
\text { inseto estéril (ao } \\
\text { rincoforol). }\end{array}$ \\
\hline
\end{tabular}

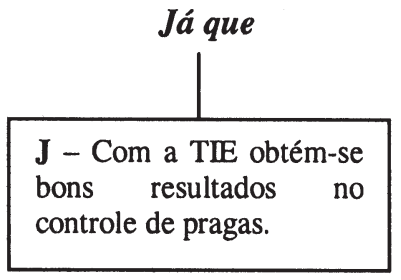

Esquema $2 S(\boldsymbol{a}) \boldsymbol{e}(\boldsymbol{b})$. Argumentos apresentados pelo grupo G2 para a resolução do caso Praga do Coqueiro

DF1 - O Sr. Francisco de Freitas, proprietário de uma fazenda de plantação de cocos, vê seu cultivo atacado por besouros, um besouro macho. $\mathrm{O}$ nome científico dele é Rhynchophorus Palmarum. DF2 - Na armadilha (alternativa para capturar os besouros) são colocados a cana de açúcar e o abacaxi dentro do balde e as cápsulas de rincoforol em cima da tampa.

DF3 - Um aspecto importante é a conscientização de todos os agricultores.

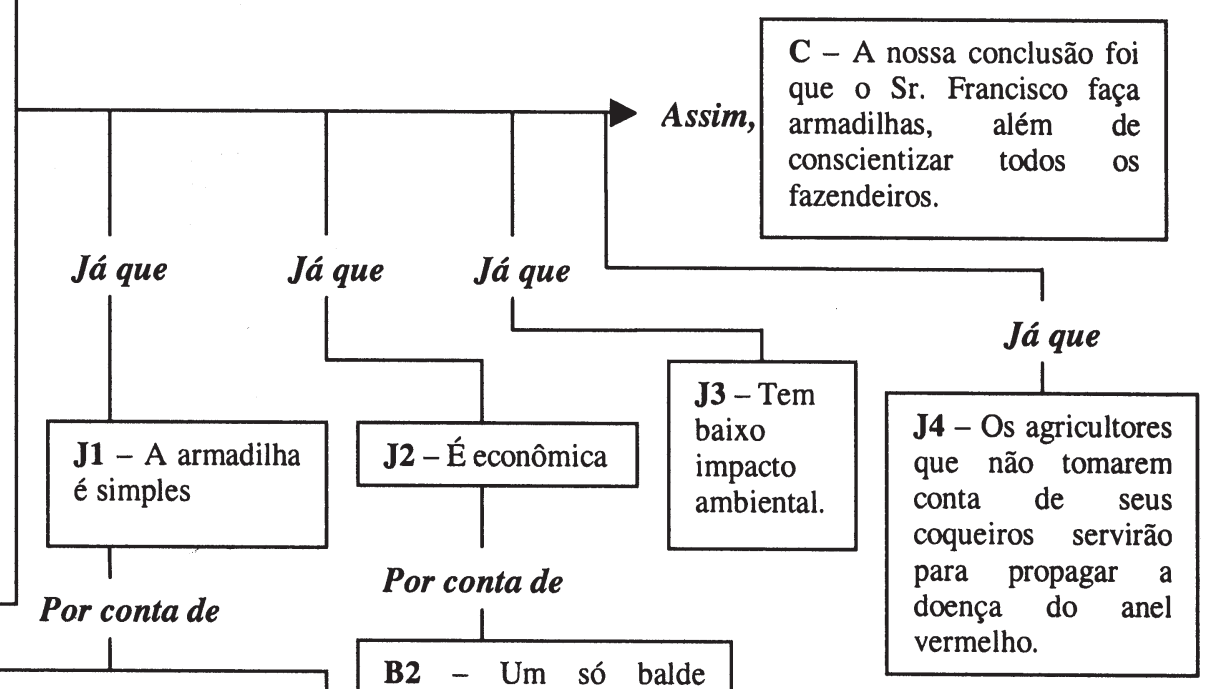

B1 - Usa apenas um balde, cana de açúcar e o abrange 3 hectares de rincoforol. 


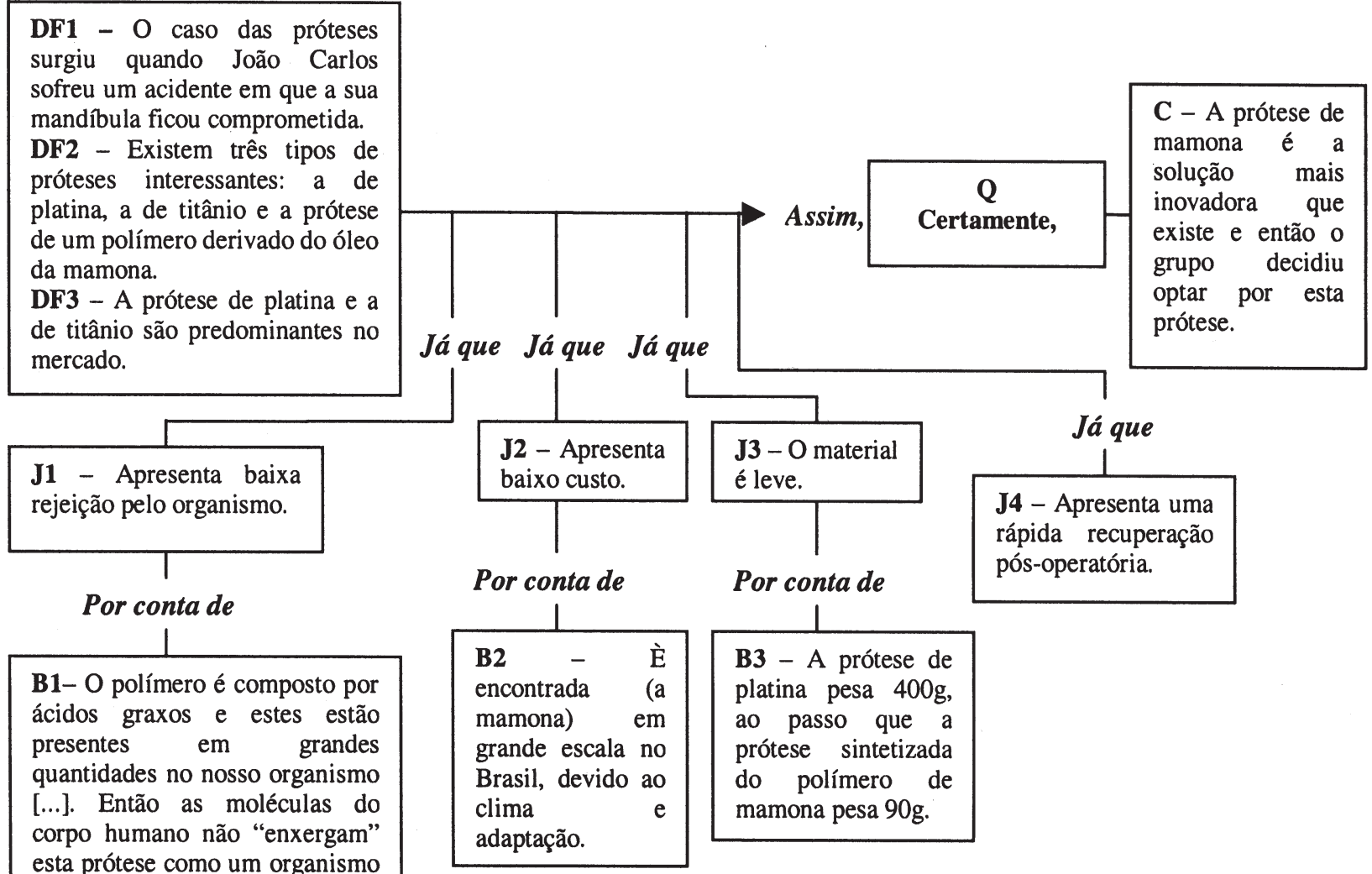

Esquema 4S. Argumentos apresentados pelo grupo G4 para a resolução do Caso das Próteses

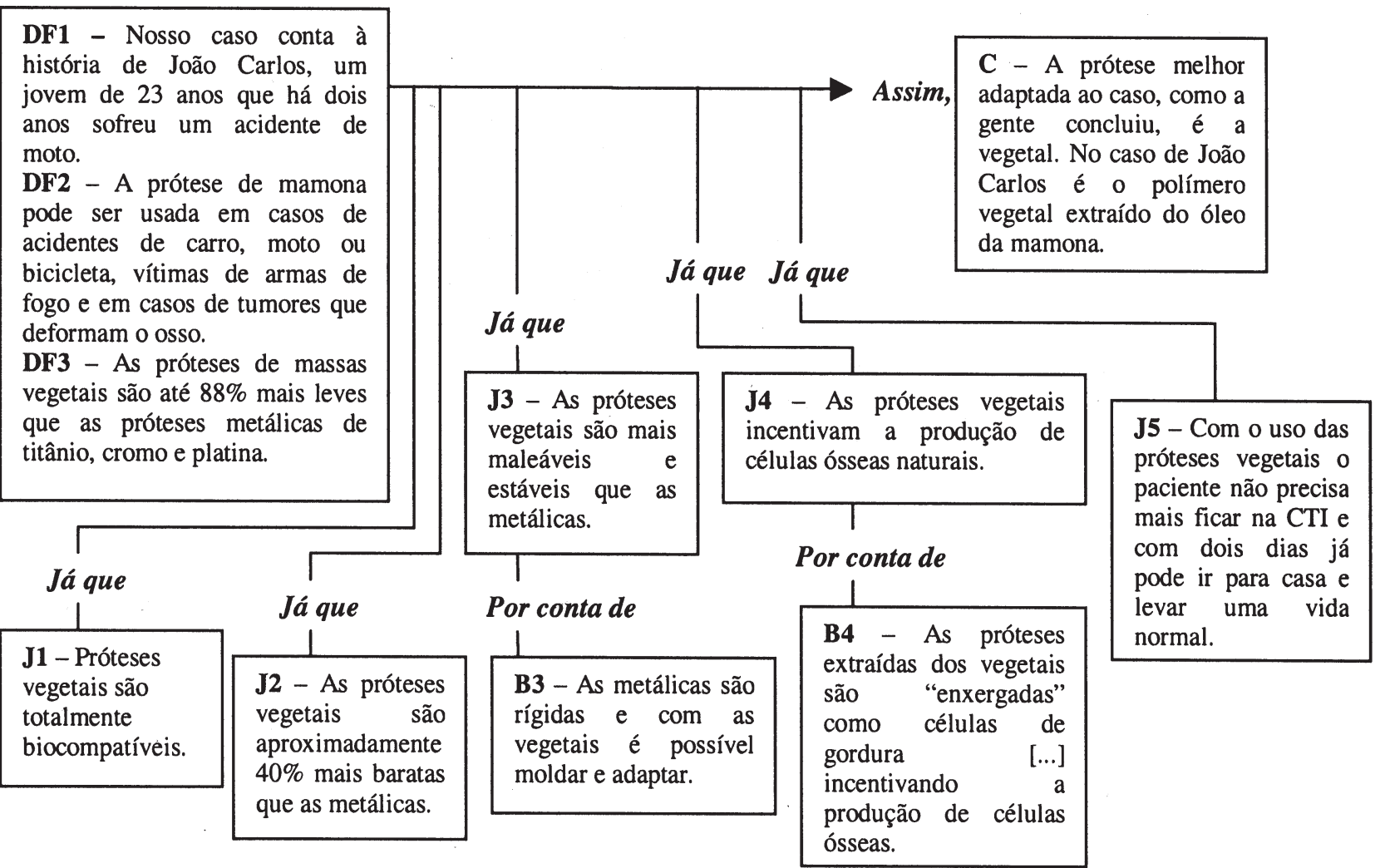




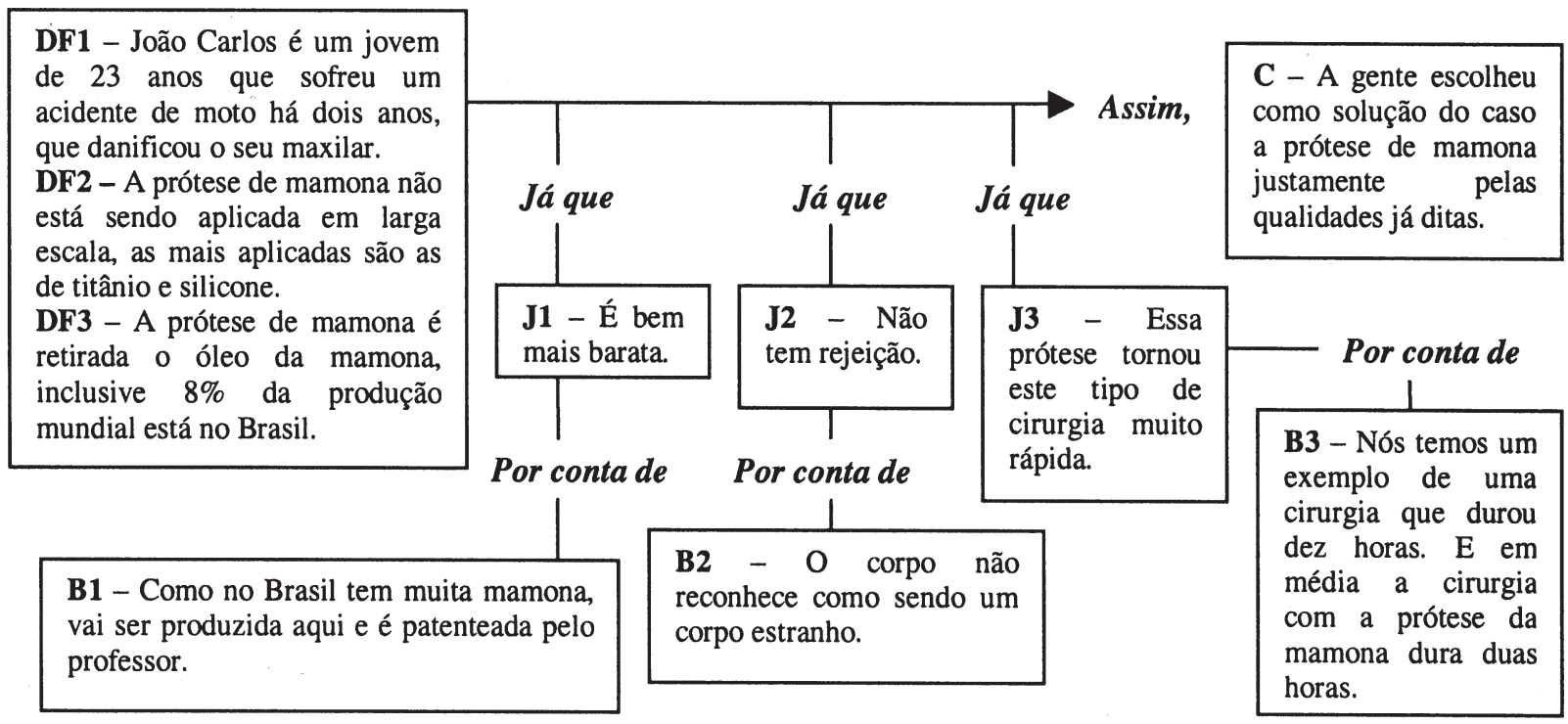

Esquema 6S. Argumentos apresentados pelo grupo G6 para a resolução do Caso das Próteses 